\title{
Paradoksal Psikoterapi
}

\section{Önder BALTACI ${ }^{1}$}

\begin{abstract}
Özet
Paradoksal psikoterapinin öncülerinden olan psikiyatrist ve nörolojist Victor Frankl çocukluğundan ve geçmiş yaşantılarından yola çıkarak logoterapi adını verdiği anlamı merkez alan anlam yoluyla sağaltımı amaçlayan anlam terapisinin kurucusudur. Kuramında logoterapi ve varoluş analizi kavramlarını kullanan Frankl'ın felsefesi özgür iradeyi ve anlam arayışını vurgular. Varoluş analizinin kişiye yüklediği en büyük görev olan sorumluluk bilincine dikkat çeken Frankl insanın tamamen özgür olmadı̆̆ını sadece hedeflerini ve isteklerini yerine getirmesi açısından özgür olduğunu dile getirir. Kişinin kendi hayatındaki anlam isteminin farkına varamaması durumunda derin bir anlamsızlık hissi ve boşluk içine düşeceğini vurgulayan Frankl bu hissin kişide psikopatolojik sorunlara yol açtığını söyler. Danışman-danışan ilişkisinin kişinin değişiminde en önemli unsur olduğunu vurgulayarak, danışmanın danışanı anlam arayışında yönlendirmesi gerektiğini ve onu bu arayışa teşvik etmesi gerektiğini dile getirir. Terapötik ilişkide paradoksik niyet ve düşünce odağını değiştirme tekniklerini kullanarak kişinin var olan anlamlarını değiştirerek onları yeniden anlamlandırmasıyla anksiyetesinin ve depresyonunun üstesinden gelebileceğini vurgular. Bu teknikler bireysel danışmada, çift danışmalarında ve grup danışmalarında uygulanır. Terapinin ilk aşamalarında kişinin anlam arayışı desteklenir ve teşvik edilir son aşamalarda danışman danışanı kendi deneyimlerinden, kendi değerlerinden ve yaşam amaçlarından öğrendiklerini somut eylemlere dönüştürmesi için teşvik eder. Paradoksal psikoterapi özetle hayatın anlamını, kişinin içsel anlam arayışını ve yeniden anlamlandırmasını içeren yeni ve gelişmekte olan birçok terapi çeşidiyle entegre çalışma olasılığı olan bir terapi çeşididir.
\end{abstract}

Anahtar kelimeler: Paradoksal psikoterapi, paradoks, paradoksik niyet

\section{Abstract}

Psychiatrist and neurologist Victor Frankl who is one of the pioneers of paradoxical psychotherapy is the founder of logo therapy based on past experiences and childhood which aims treatment by means and takes meaning in the center. Franklin's philosophy using the concepts logo therapy and existential analysis in his theory emphasizes the free will and search for meaning. Franklin drawing attention to the sense of responsibility that is the biggest task existential analysis expresses human being is not completely free but only free in terms of fulfilling the goals and aspirations. Franklin emphasizing that the person who fails to realize the meaning of his life will fall into a deep sense of meaninglessness and emptiness makes clear that this feeling leads to occurrence of psychopathological problems. Emphasizing that counselor-consultant relation is the most prominent element of individual change, Franklin expresses that the counselor should lead and encourage the consultant to seek the meaning. By using dereflection methods and paradoxic intention in therapeutics relation, Franklin emphasizes that the person will be able to overcome anxiety and depression by changing and re-interpreting the meaning. This is applied in individual counseling, pair counseling, and group counseling. in the first paces of the therapy, the meaning search of person is supported and encouraged. in the last paces, the counselor encourage the consultant to learn from his own life experiences, values, and goals by turning them into concrete actions. In summary, paradoxical psychotherapy is a kind of therapy that includes the personal pursuit and re-interpretation of the meaning of life, and has a potential to integrate many other therapy kinds.

Keywords: paradoxical psychotherapy, paradox, paradoxic intention

\section{GİRIŞ}

Türkçe'ye Fransızca kökenli “paradoxe” sözcüğünden türeyerek giren paradoks, görünüşte doğru olan bir ifade veya ifadeler topluluğunun bir çelişki yaratması veya sezgiye

${ }^{1}$ Arş. Gör., Ahi Evran Üniversitesi, Eğitim Fakültesi, baltacionder@gmail.com 
karşı bir sonuç yaratması anlamında kullanılır (Hançerlioğlu, 2000). Yunanca da "paradoxos" olarak kullanılan bu terimin Türkçe'deki karşılığ1 "yanıltmaç", "çelişki" ve "çatışkı" sözcükleridir. Paradokslar kendi içlerinde çelişkiliymiş gibi görünen, mantıksal olarak hem doğruluğu, hem de yanlışlığı kanıtlanabilen önermelerdir (Weeks ve L'Abate, 1982; Weeks, 1991).

Mantıkçılar paradoksları üçe ayırır. Bunlar çatışkı (antomia), semantik çatışkı ve pragmatik paradokstur (Weeks, 1991). Çatışkı, gerçekte ya da görünüşte birbirleriyle uyuşmayan ifadeler anlamina gelir (Haim, 1985). Pragmatik paradoks, paradoksal psikoterapinin kaynağını oluşturur. Paradoksal psikoterapi, kişinin kendisini değiştirmeden değişmesini amaçlar. Kişisel sorumluluk ve öz belirlenimcilik önemli kavramlarındandır. Kişinin hem seçim yapmasından, hem de bu seçimlerden ve yaşamının yönünü belirlemeden sorumlu olduğunu belirtir (Weeks, 1991).

Yeni ve yayginlaşmakta olan paradoksal psikoterapi ilk olarak aile ve sistem odaklı terapistler tarafından kullanılmaya başlanmıştır. Varoluşsal, hümanistik ve bilişseldavranışsal terapistler tarafından da uygulanıldığı alanlar olduğu gözlemlenmiştir (Jr ve McCarthy, 2007).

\section{Paradoksal Psikoterapinin Tarihçesi}

Paradoksal psikoterapinin temelinin "Bireysel Psikoloji"nin ekolün öncüsü olan Alfred Adler'e (7 Şubat 1870 - 28 Mayıs 1937) dayandığ düşünülmektedir. Adler, paradoksal stratejileri kullanan ve onunla ilgili çalışmalar yapan ilk kişilerdendir (Frankl, 1967; Gerald, Frank ve Lisiecki, 1976). Bireyin fenomenolojik dünyasına ve algılarına ağırlık veren Adler, bireylerin yaşamlarına atfettikleri anlamları araştırmıştır. Yaşantılarımızı yaratma, eylemleştirme ve anlamlandırmamıza göre davrandığımız düşüncesini savunur (Frankl, 1985). Adler' in çalışmalarında Nietzche ve Hegel' in diyalektik düşüncelerinden etkilendiği gözlemlenmiştir.

Paradoksal psikoterapinin en belirgin kullanıldığı çalışmalar Victor Frankl'ın çalışmalarıdır (Weeks, 1991). Victor Frankl, Psikanaliz ve Bireysel Psikoloji'den sonra "Üçüncü Viyana Psikoterapi Ekolü" olarak meşhur olan Logoterapinin öncülerindendir. Bunun yanı sıra çalışmalarında "varoluş analizi" kavramını da kullanır (Weeks ve L'Abate, 1982).

\section{Victor Frankl'in Hayatı}

26 Mart 1905 'de Viyana'da dünyaya gelen psikiyatrist ve nörolojist Victor Frankl nöroloji ve psikiyatri alanında depresyon ve intihar konularında uzmanlığını yapmıştır. Çalışmalarında Sigmund Freud ve Alfred Adler'den etkilendiği görülmüştür (Weeks ve L'Abate, 1982). Kuramının temellerinin çocukluğunda atıldığını dile getirir. Dört yaşlarında, herkes gibi bir gün kendisinin de öleceği fikriyle ansızın irkildiğinden bahseder. Yaşadığı bu tecrübe O'nda ölüm korkusundan çok, hayatın anlamının bunca yaşananlarla birlikte ölümle yok olup olmayacağı sorusunu aklına getirmiştir ve endişelenmiştir (Frankl, 1985a). Bu endişesini, bir gün hocası, hayatın bir oksidasyondan, bir yanma mekanizmasından ibaret olduğunu dile getirdiğinde, "Eğer hayat anlattı̆̆ınızdan başka bir şey değilse, o zaman bütün bu yaşadıklarımızın ne anlamı var?!" sözüyle dışa vurur (Frankl, 1985b). Ayrıca intihar eden öğrenci arkadaşının elinde açık vaziyette Neitszche'ye ait bir kitabın bulunması, Frankl' da dünya görüşü ile hayatın oluşumu arasında varoluşsal bir bağın olması gerektiği düşüncesini doğurur. Ve böylece Frankl'ın kuramının temelleri atılmış olur (Frankl, 1985a). Frankl II. Dünya savaşı sırasında Nazi kamplarında yaşamış, eşini, annesini ve babasını bu kamplarda kaybetmiştir. Psikoloji, psikiyatri ve psikanaliz bilgilerini kullanarak bu kamplarda yaşananları ve yaşayan insanları gözlemleyen Frankl bu kampları "tünelin sonunda her zaman bir 1şık gören, hayata ümitle ve anlam duygusuyla bağlanan insanlar buralarda hayatta kaldı. Anlam boşluğu psikolojik yönden yıpratıcıdır. Yaşamı anlamlı olan 
kişiler her türlü dış tehlike ve zorluklarda yaşamlarını sürdürebilirler." şeklinde yorumlamıştır (Frankl, 1985a). Bugüne kadar otuz dokuz adet kitabı yayımlanan psikiyatristin "Duyulmayan Anlam Çı̆̆lığı" ve "İnsanın Anlam Arayışı" Türkçe' ye çevrilmiş yapıtlarındandır. 2 Eylül 1997' de kalp yetmezliğinden hayatını kaybetmiştir (Fehr, 2000).

\section{Victor Frankl'ın Kişilik Kuramı ve İnsan Doğasına Bakışı}

Frankl'ın kuramının odaklandığı felsefi ve psikolojik kavramlar temelde istek özgürlüğ̈̈, anlam istemi ve anlam arayışıdır. Kişinin öznel yaşantılarını anlamaya yönelik bir felsefedir (Frankl, 1985a).

Frankl'a göre insan bedensel (somatik), zihinsel (mental) ve psikolojik ya da ruhsal boyutlarına sahip bir bütünlüktür. İnsan doğuştan getirdiği bir takım kalıtsal dürtülere ve karakteristiklere sahiptir. Jung, Freud ve Adler insanın bedensel ve mental boyutları üzerine derinlemesine araştırma yaparlarken, (Jr ve McCarthy, 2007), Frankl ruhsal boyut üzerine derinlemesine araştırmalar yaparak insan doğasını, insanın ruhsal ya da psikolojik boyutunu ele alarak açılar (Nietzel, Bernstein, Kramer ve Milich, 2003). Ruhsal boyut fenomonolojik olarak anlık öz farkındalıklarda ortaya çıkmakla birlikte kaynağı ruhsal bilinçdışıdır. Vicdan, aşk ve estetik bilinç ruhsal boyutun ürünüdür (Nietzel, Bernstein, Kramer ve Milich, 2003).

Varoluş analizi kavramlarına göre; insanlar tamamen koşullara tabi değillerdir. Temelde karar verme ve içsel ve dışsal koşullar karşısında duruş takınma yetilerine sahiptirler (Weeks ve L'Abate, 2013). İçsel koşullar kişi kaynaklı psikolojik durumlar, dışsal koşullar dışarı kaynaklı biyolojik ve sosyal koşullar olarak açıklanabilir. Burada özgür irade kavramındaki “özgürlük" kişinin kendi hayatını verilen olanakların sınırları içinde şekillendirme alanı olarak tanımlanır (Nietzel, Bernstein, Kramer ve Milich, 2003). Kişinin yaşamdaki seçimlerinin farkında olduğu yani sınırların var olduğu görüşünü dile getirir (Jr ve McCarthy, 2007).

Frankl'a göre anlam hiçbir zaman yok olmamaktadır ancak her zaman değişime uğrayabilir. Kişi anlamını üç farklı yoldan bulabilir (Nietzel, Bernstein, Kramer ve Milich, 2003). Bir eser yaratarak ya da bir iş yaparak, bir insanla etkileşime girerek ya da bir şey yaşayarak ve son olarak kendi yaşantısından da görüldüğü gibi kaçınılmaz olan acı durumuna karşı bir duruş, tavır geliştirerek (Frankl, 1985a).

İnsan tamamen özgür değildir ancak hedeflerini ve isteklerini yerine getirmesi açısından özgürdür. Anlam arayışı kişinin en temel motivasyonudur (Weeks, 1991). Bu anlam arayışında kişi, tüm olasılıkları araştırma, seçimleri deneme ve ileriye gitme anlamına gelen otantikliğin yani olasılıkları keşfetme ve gerçekleştirmenin peşinden gitmelidir (Weeks ve L'Abate, 2013). Eğer kişi kendi hayatındaki anlam isteminin farkına varamaz ise derin bir anlamsızlık hissi ve boşluk hisseder. Yaşamdaki bu tamamlanmamışlık ve doyum eksikliği kişinin kendini suçlu hissetmesine yol açar. Bu anlamsızlık ve boşluk hissi diğer bir deyişle varoluşsal boşluk, engellenme agresyona, bağımlılığa, depresyona ve intihara sebep olabildiği gibi psikosomatik sorunlara ve nevrotik bozukluklara da yol açabilir (Haim, 1986).

\section{Logoterapi}

Yunanca kelime "logos"dan adını alan logoterapi Victor Frankl öncülüğünde kurulmuş, yaygınlaşmakta olan yeni bir psikoterapik yaklaşımdır (Frankl, 1985b). Logoterapi "anlam" 1 merkez olarak alıp, anlam kazandırma yoluyla sağaltımı amaçlar. Frankl'a göre insandaki temel güdüleyici güç, yaşamını anlamlı kılma veya bir anlam bulma çabasıdır (Frankl, 1975). Bu çabası başarısızlıkla sonuçlanan kişilerde varoluşsal boşluk ortaya çıkar ve kişi kendini ve yaşamını yalnız, anlamsız ve boşuna yaşanmış hisseder (Ascher ve Schotte, 1999). Logoterapinin amacı kişinin kendine özgü bir amaç, yaşamasını sağlayacak ve bu varoluşsal boşluğu dolduracak bir anlam bulmasını sağlamaktır (Ascher, 1989). 


\section{Danışman- Danışan İlişkisi}

Logoterapi danışanın kendi sorumluluklarının tam olarak farkına varmasını sağlamayı amaçlar; bu nedenle kişiye, neye karşı, ne için ya da kime karşı sorumlu olduğunu anlaması seçeneğinin bırakılması gerekir (Ascher ve Efran, 1978).

Varoluşsal terapilerde ve logoterapide "değişim" de danışman ve danışan arasındaki ilişki önemli rol oynar (Ascher, 1989). Danışmanın rolü, danışanına varoluşsal gerçeklerle yüzleşmesinde, hayatın anlamını ve kendi amacını keşfetmesinde yardımcı olmaktır. Danışanı, anlam arayışında cesaretlendirerek, onun hayatına anlam kazandırabileceği amaç ve hedefler bulmasını sağlamaktır (Ascher ve Schotte, 1999).

Danışanının hayatı suçluluk, eksiklik, acı ve sıkıntılarla dolu olsa bile, danışman danışanın bunlarla yüzleşmesinde yardımcı olma çabasındadır. Geçmişinde yaşadıkları ne olursa olsun bireyin bütüncü ve sorumlu bir hayat felsefesi kazanmasına yardımcı olmaktır (Weeks, 1991).

\section{Logoterapide Kullanılan Psikolojik Danışma Teknikleri}

Logoterapide kullanılan psikolojik danışma teknikleri paradoksik niyet, düşünce odağını değiştirme ve tutumların değiştirilmesidir.

Paradoksik Niyet; Bu teknik daha önce Adler tarafından "semptomu reçetelendirme" ve Dreikurs tarafından "anti-öneri" olarak tanımlanmıştır. Bu teknikte danışanlar semptomlarını daha da geliştirmek için cesaretlendirilirler (Sharf, 2014). Korkunun, korkulan şeyi yarattığı ve aşırı niyetin, arzulanan şeyi imkânsızlaştırdığı gerçeğine dayanmaktadır. Korkunun bir nesnesi de korkunun kendisidir, danışanlar sık sık "kaygı konusunda kaygıdan" söz ederler. Korku korkusuna yönelik temel tepki korkudan kaçmaktır. Birey kaygısını alevlendiren durumlardan kaçınmaya başlar, yani korkusundan kaçar (Ascher, 1989).

Belli bir semptom, bireyde tekrar ortaya çıkabileceği konusunda bir beklenti yaratır. Bir semptom fobiyi uyandırır, karşılık olarak fobi semptomu kamçılar ve semptomun yeniden ortaya çıkması fobiyi pekiştirir. Kısır döngü oluşur. Danışan fobik belirtiler sergiliyor ise korktuğu şeyi yapmaya, obsesif-kompulsif belirtiler sergiliyor ise korktuğu şeyin olmasını arzulamaya yönlendirilmektedir. Böylece danışanın korkularından kaçmasına ya da korkularıyla mücadele etmesine son verilmiş olur. Böylelikle hastalık yaratan (patojenik) korkunun yerini, paradoksik (çelişkili) bir niyet ya da arzu alır, sonuç olarak da beklenti kaygısının kısır döngüsü kırılmış olur (Frankl, 2007).

Paradoksik niyet tekniği uygulanırken insana özgü mizah yeteneğini harekete geçirmek önemlidir (DiTomasso ve Greenberg, 1989; Frankl, 1967). İnsan kendisiyle eğlenme, kendine gülme ve kendi korkularıyla dalga geçme gibi özelliklere de sahiptir. Terlemekten korkan bir danışan kendisini izleyenlere terlemenin gerçekten neye benzediğini göstermekten ve giysilerini islatacak kadar terlediğini düşünmekten zevk alacaktır (Budak, 2005).

Kişi saplantılarıyla boğuşmaktan vazgeçtiği ve bunun yerine saplantılarını alaycı bir tavırla ele alıp, espri konusu yaptığı anda, kısır döngü kesilmektedir (Budak, 2005). Birey kendi nevrotik korkularıyla alay etmekle kalmayacak, zamanla korkularını görmezlikten gelmeye başlayacaktır (DiTomasso ve Greenberg, 1989).

Paradoksik niyet daha çok anksiyete bozuklukları yaşayan danışanlar için kullanılan bir tekniktir. Frankl'a göre hayatımızdaki korkular bir kısır döngü gibi giderek artar. Yükseklik fobisi, köpek fobisi gibi belirli durumlarda ortaya çıkan fobilerin kişinin kendisinin geliştirdiğini savunur (Frankl, 1967). Kişinin bu fobilerden kaçtığını ve kaçarken anksiyetesinin arttığını ve bu anksiyetenin kişinin fobisini daha çok güçlendirdiğini, bunun bir kısır döngü olduğunu dile getirir. Paradoksik niyetin amacı bu kısır döngüyü kırmaktır (Ascher ve Efran, 1978). 
$\mathrm{Bu}$ teknikte danışandan olmasından en çok korktuğu şeyin olmasını arzulaması istenir. Örneğin; terlemekten ve kızarmaktan korktuğu için topluluk içinde konuşmaktan çekinen kişiye, bir dahaki sefere toplum içinde konuşurken kendisine şunu söylemesi istenir. “O kadar çok terleyeceğim ki, dünyadaki en sulu ve kırmızı insan ben olacağım!" Burada kişi yaşadığı deneyimin anlamını değiştirir, o deneyime başka bir anlam kazandırarak korkularından ve semptomlarından uzaklaşır (Ascher, 1989; Budak, 2005).

Paradoksik niyet uyku bozukluklarında, obsesif kompulsif bozukluklarda ve fobik bozukluklarda kullanılır (Ascher ve Schotte, 1999). Bu teknik birçok durumda kısa süreli terapilerde kullanilır (Solyom, Garza-Perez, Ledwidge ve Solyom, 1972).

Düşünce Odă̆ını Değiştirme; Bu teknik daha çok "aşırı düşünme" sebebiyle sıkıntı çeken danışanlar için kullanılır. Aşırı düşünme, bir şeyin olmasından aşırı korkmanın, korkulan şeyin olmasına yol açması olgusunu anlatmak için kullanılan terimdir (Ascher, 1989). Aşırı düşünme durumu cinsel nevrotik yapılarda sıklıkla ortaya çıkmaktadır. Düşünce odağı değiştirme tekniğinde bir şeye karşı değil cinsel haz için mücadele için uğraşır. Fakat hazzın ne kadar amaçlanırsa o kadar elden kaçırılacağı, logoterapinin temel ilkelerinden birisidir (Frankl, 2007). Örneğin; topluluk içinde konuşurken kızarmaktan korkan kişinin, daha çok kızarması, kekelemekten korkan kişinin daha çok kekelemesi gibi. Düşünce odağını değiştirme; kişinin, kafasını sürekli meşgul eden sorunlardan, semptomlardan uzaklaşarak düşüncelerini başka insanlara, uğraşlara yöneltmesidir (Ascher ve Schotte, 1999). Örneğin; yoğun kaygı anında kişiye derin nefes alması ve kas gevşetme hareketleri yapması önerilir. Bu teknik seksüel bozuklukların ve anksiyete bozukluklarının sağaltımında kullanilir.

Davranışsal terapinin tekniklerine benzerliğiyle dikkat çeken logoterapi varoluşsal olarak yaşanılan deneyimlerin anlamlarının değiştirilmesi ve o deneyimlere yeni anlamlar kazandırmak olarak yorumlanabilir (Frankl, 1985a). Böylece kişi hayatta amacını ve anlamını bulma konusunda sorumluluk üstlenmiş olur.

Tutumların Değiştirilmesi; Psikolojik bir objeye yönelik atfedilen her şey tutum olarak değerlendirilir (Kağıtçıbaşı, 2008). Danışanlar yaşam koşulları olumlu dahi olsa kendileriyle ilgili olumsuz tutumlara sahip olabilirler. Kişinin kendisini çaresiz hissettiği, zor koşullar yaşadığı dönemler olabilir. Logoterapinin amacı danışanın durumla ilgili düşünce biçimini değiştirmektir (Ascher ve Schotte, 1999). Tutumların değiştirilmesi tekniği danışanın tutumlarının paylaşılması, tutumlarıyla ilgili tartışılması, ona yeni öneriler getirilmesi yoluyla uygulanabilir. Bu teknik danışanın yaşantıladığıyla, içinde bulunduğu durumla ilgili yeni bir bakış açısı kazandırılmasıdır. Kişi geçmişte olumsuz deneyimler yaşantılamıştır ancak geçmiş hakkındaki düşünce şeklini geçmişe olan yaklaşımı değiştirebilir (Budak, 2005).

\section{Psikolojik Danışma Süreci}

Psikolojik danışma sürecinin ilk aşamasında, ilk olarak danışman- danışan arasında güvenilir bir ilişki kurulması esastır (Jr ve McCarthy, 2007). Danışan kendi iç dünyasını keşfederken bu güveni ve özgürlügü hissetmelidir. Danışman danışanına kişisel anlamlarını araştırırken bir bilge kişi gibi yol göstermelidir ve onu cesaretlendirmelidir (Weeks ve L'Abate, 2013).

Danışanların terapilerden beklentilerinin çok yüksek olduğu ve değişimin hemen gerçekleşmesini istedikleri göz önüne alındığında danışman ilk aşamada danışanını terapinin içeriği, yapısı ve süreci konusunda bilgilendirmelidir (Nietzel, Bernstein, Kramer ve Milich, 2003).

Terapinin orta aşamalarında danışanın değer sistemi ve kendi deneyimlerine dayalı anlam arayışına devam edilir. Danışman Danışana içsel psikolojik dünyasını keşfetmesinde 
yardımcı olur. Kişi kendisini diğer ilişkilerinde, soysal çevresinde keşfetmeye başlar. Kişi anlam arayışının ve varoluşunun farkına vardığında, danışman onu bu aşamada sorumluluklarıyla yüzleştirerek sorumluluk bilinci kazanmasına yardımcı olur (Nietzel, Bernstein, Kramer ve Milich, 2003).

Daha sonraki aşamalarda danışman danışanı kendi deneyimlerinden, kendi değerlerinden ve yaşam amaçlarından öğrendiklerini somut eylemlere dönüştürmesi için teşvik eder. Paradoksal niyet, düşünce odağını değiştirme ve tutumların değiştirilmesi gibi teknikleri kullanarak, yaşantılarına yeni anlamlar yükleyen kişi anksiyetesinin, depresyonunun bu şekilde üstesinden gelir (Ascher ve Schotte, 1999).

\section{Paradoksal Psikoterapinin Uygulama Alanları}

Paradoksal psikoterapi bireysel terapilerde, aile ve çift terapilerinde, cinsel terapide ve grup terapilerinde uygulanır (Nietzel, Bernstein, Kramer ve Milich, 2003; Frankl, 2007).

Frankl her çatışmanın her zaman nevrotik olmadığından bahseder. Bir ölçüde çatışma normal ve sağlıklıdır. Benzer bir şekilde acı çekmek her zaman için patolojik bir olgu değildir, acı nevrotik bir semptom olmaktan çok, özellikle varoluşsal engellenmeden kaynaklanıyorsa, bir başarı anlamına da gelebilir. Frankl'a göre hayatın anlamında "acı" da bulunur ve kişinin ne olursa olsun hayatın zorluklarına bu "acı"lara karşı duruşu önemlidir (Frankl, 1985a). Geçmiş yaşantılarından ve gözlemlerinden de yola çıkarak insanların "acı"nın farkına genellikle ciddi ve hayatı tehdit eden bir durumla karşılaştıklarında vardıklarını dile getirir (Frankl, 1967).

Bireysel danışmada, logoterapinin kanser gibi hastalıklarda ya da ileri yaştaki danışanlarla kullanıldığı gözlemlenmiştir. Kişinin böyle bir deneyimle; geçmiş yaşantılarını gözden geçirdiği ve o anki yaşadığı "acı"yla yeni bir anlam arayışına girdiği düşünülür. Anlam arayışı sonucu o anki durumuna yeni anlam katarak anksiyetesinin ve depresyonunun bu şekilde üstesinden gelebildiği ifade edilir. Varoluş psikoterapistlerinden Yalom'un da bu danışanlarda varoluş analizi üzerine çalıştı̆̆ı gözlemlenmiştir (Jr ve McCarthy, 2007).

Bireysel danışma alan bir diğer danışan grubu anksiyete bozukluğu olan danışanlardır (Ascher ve Schotte, 1999; Frankl, 2007). Fobik bozukluklarda, cinsel işlev bozukluklarında ve obsesif kompulsif bozukluklarında sıklıkla uygulanır (Ascher ve Schotte, 1999; Frankl, 2007). Logoterapi motive edici özelliğinin yanına davranışsal psikoterapiye benzeyen yönüyle de dikkat çekmektedir.

Grup terapilerinde, varoluşçu psikoterapist grup üyeleri ile işbirliği kurmada kolaylaştırıcı olarak iş görür ve üyeler arasında anlamlı ve güvenilir bir ilişki kurmaya çalışır. Üyelerin dünyada varoluşu gerçekleştirmeleri için öznel duygularını ifade etmelerine yardımcı olur (Frankl, 1967). Grup üyeleri anlam arayışları ile varoluşlarının farkına vardıklarında, grup lideri üyeleri sorumluluklarıyla ve özgür iradeleriyle yüzleştirir. Grup lideri, grup üyelerini yaşamdaki başarıları üzerine düşünmeye ve doyum ve otantiklik düzeylerini belirlemeye teşvik eder (Frankl, 1967).

Paradoksal psikoterapinin uygulandığı bir diğer alanda çift terapisidir. Danışman ve çiftler arasında kurulan terapötik ilişki, çiftlerin sorumluluklarının ve özgürlüklerinin farkına varmaları açısından önemlidir. Terapist ilişkide deneyimlenen acıya ve çatışmaya odaklanarak, çiftlerin ilişkilerinde neyin iyi gidip neyin gitmediğini değerlendirmelerine yardımcı olur (Jr ve McCarthy, 2007). Varoluşsal terapide olduğu gibi burada da terapistin temel görevi çiftleri, ilişkilerindeki anlam arayışına teşvik etmektir.

\section{TARTIŞMA, SONUÇ VE ÖNERILLER}

Paradoksal psikoterapi, kendine has psikoterapik teknikleri geliştiren bir terapi türüdür. Diğer psikoterapi kuramlarından farklı olarak kişilik gelişiminde anlam ve 
sorumluluk bilincinin önemini vurgulama açısından farklı bir bakış açısına sahiptir (Jr ve McCarthy, 2007). Travma yaşantılamış, istismara uğramış, psikopatolojik ve ciddi rahatsızlığı olan insanlar, içinde bulundukları durum sebebiyle hayatın anlamı arayışına girerler. Paradoksal psikoterapi, terapideki danışman rolünün de etkisiyle bu danışanları anlam arayışında teşvik etmek, onlara yol göstermek açısından uygulanabilecek en uygun terapi denilebilir (Nietzel, Bernstein, Kramer ve Milich, 2003).

Paradoksal psikoterapinin, psikanalitik ve davranışsal psikoterapiler gibi diğer terapilerle entegre bir çalışma yürütme olasılığı yüksektir (Weeks, 1991). Danışan- danışman ilişkisi açısından esnek bir yapıya sahiptir, danışana kendini özgür ve güvende hissetme olanağ1 sağlar (Weeks ve L'Abate, 2013).

Paradoksal psikoterapinin deneysel bir araştırma yapısına sahip olmaması sebebiyle, deneysel sağaltımı olup olmaması konusunda soru işaretleri vardır (Jr ve McCarthy, 2007). Sadece belirli sorunlara uygulanan bir terapi türü olduğundan bu teknikle bütün sorunların sağaltımı mümkün değildir (Ascher ve Schotte, 1999). Teknik içinde yer alan aldatmaca uygulamalar etik yönünden sorunlara neden olabilmektedir (Glen ve Darrell, 1985). Danışmanın danışana aktif bir müdahalesi olmadığından, sağaltım sonucu her zaman olumlu olmayabilir. Terapi süreci danışan-danışman ilişkisinden etkilenebildiği gibi danışman her durumda aynı oranda başarılı olamayabilir (Ascher, 1989).

Varoluşsal terapinin bir türü olan logoterapinin kullandığ kavramlar ve yöntemler olarak analitik ve davranışsal terapilerden sonra psikoterapiye yeni bir boyut kattığ1 tartışılmazdır. Kişinin anlam arayışı üzerine odaklanması, yaşamda anlam istemi ve anlam arayışı, anlam gerçeğinin farkına varması sonucu karşısına çıkan zorluklar ne olursa olsun ona olan duruşunun önemli olduğu gerçeği vurgulanmaktadır. Paradoksik niyet ve düşünce odağını değiştirme gibi kullandığı farklı tekniklerle anksiyete ve nevrotik bozuklukların sağaltımında etkili bir yöntem olduğu gözlemlenir. Ancak uygulama alanlarının sinırlı olması eleştirilebilecek bir yönüdür. Varoluş analizi üzerine odaklanan dünyadaki anlam arayışı, anlamlandırma gibi kavramlar üzerinde odaklanması diğer ağır psikopatolojik rahatsızlıkların sağaltımında kullanılamayacağı gibi, uygulandığı alanlarda da her danışandan aynı verim alınamaması konusunda logoterapiye eleştirel bir bakış açısı geliştirilebilir. 
Cumhuriyet International Journal of Education-CIJE

e-ISSN: 2147-1606

Vol 5 (2), 2016, 1 - 8

\section{KAYNAKÇA}

Ascher, L. M. (1989). Paradoxical intention and recursive anxiety. In L. M. Ascher (Ed.), Therapeutic paradox (pp.93-137). New York: Guilford Press.

Ascher, L. M., \& Efran, J. (1978). Use of paradoxical intention in a behavioral program for sleep onset insomnia. Journal of Consulting and Clinical Psychology, 46, 547-550.

Ascher, L. M., \& Schotte, D. E. (1999). Paradoxical intention and recursive anxiety. Journal of Behavior Therapy and Experimental Psychiatry, 30, 71-79.

Budak, S. (2005). Psikoloji Terimler Sözlüğ̈̈ .Ankara: Bilim ve Sanat Yayınları.

DiTomasso, R. A., \& Greenberg, R. L. (1989). Paradoxical intention: The case of the case study. In L. M. Ascher (Ed.), Therapeutic paradox. New York: Guilford Press.

Fehr, S.S. (2000). Grup Terapisine Giriş. İstanbul:Sistem Yayıncılık.

Frankl, V. (2007). Duyulmayan Anlam Çı̆̆̆ı̆̆ı. İstanbul:Öteki Ajans.

Frankl, V. (1967). Psychotherapy and existentialism: Selected papers on logotherapy. New York: Simon \& Schuster.

Frankl, V. (1975). Paradoxical intention and dereflection. Psychotherapy: Theory, Research, and Practice, 12,226-237.

Frankl, V. (1985). Logos, paradox, and search for meaning. In M.J. Mahoney \& A. Freeman (Eds) Cognition and psychotherapy. New York: Plenum Press.

Frankl,V. (1985). Man's search for meaning. New York: Washington Square Press.

Gerald, M., Frank, M. \& Lisiecki, J. (1976). The paradox in psychotherapy: An Adlerian perspective. Individual Psychology, 32(2),169-184.

Glen,K. \& Darrell, S. (1985). Reframing paradoxical psychotherapy. Psychotherapy: Theory, Research, Practice, Training, 22(4), 786-792.

Haim, O. (1986). Integrating paradoxical interventions in the normal course of therapy: a non-specific approach. Journal of Psychotherapy, 40, 572-581.

Hançerlioğlu, O. (2000). Felsefe Sözlüğü. İstanbul : Remzi Kitabevi

Jr., J.A. \& McCarthy. J.C. (2007). Theories of Counseling and Psychotherapy. New Jersey: Pearson.

Kağıtçıbaşı, Ç. (2008). Günümüzde İnsan ve İnsanlar. İstanbul:Evrim Yayınevi.

Nietzel, M.T., Bernstein, A.D., Kramer, G.P., \& Milich, R. (2003). Introduction to Clinical Psychology. New Jersey:Pearson.

Sharf, R.S. (2014). Psikoterapi ve Psikolojik Danışma Kuramları. (Çev.Edt. Nilüfer VOLTAN ACAR). Ankara:Nobel Yayınevi.

Solyom, L., Garza-Perez, J., Ledwidge, L. \& Solyom, C. (1972). Paradoxical intention in the treatment of obsessive thoughts:A pilot study. Comprehensive Psychiatry, 13(3),291-297.

Weeks, G. R., \& L'Abate, L. (1982). Paradoxical psychotherapy. New York: Brunner/Mazel.

Weeks, G.R.(1991). Promoting change through paradoxical therapy. New York: Brunner/Mazel. 